\title{
Motivação para o aprendizado em estudantes de graduação em Psicologia
}

\author{
Marcos Vinícius de Araújo \\ Johny Welton Brito da Silva' \\ Erich Montanar Franco \\ Universidade Presbiteriana Mackenzie, São Paulo - SP - Brasil
}

\begin{abstract}
Resumo: O estudo da motivação tem mostrado importante valia na compreensão dos processos de ensino aprendizagem. Uma das abordagens que estudam esse constructo, a teoria da autodeterminação, compreende que o homem é movido pela satisfação de necessidades psicológicas básicas de autonomia, competência e pertencimento, possuindo estilos motivacionais que vão da desmotivação até o comportamento intrinsicamente motivado. A presente pesquisa teve por objetivo investigar, por meio de entrevista semiestruturada, a motivação para aprender em 20 universitários do curso de Psicologia. Os resultados demonstraram estudantes com perfis motivacionais mais autônomos, com diferentes orientações motivacionais simultâneas. Verificaram-se a importância da participação de fatores ambientais e o valor da tarefa na promoção da motivação para aprender. Concluiu-se que a educação deve ser ampliada para tornar-se mais problematizadora e convidar os estudantes a admirar o mundo em parceria com os educadores, para que ambos possam ser capazes, em um movimento de práxis, de repensar a teoria e produzir novos conhecimentos.
\end{abstract}

Palavras-chave: motivação; aprendizagem; educação; teoria da autodeterminação; universitários.

\section{MOTIVATION TO LEARN IN UNDERGRADUATE STUDENTS OF PSYCHOLOGY}

\begin{abstract}
The study of motivation has shown important value in the comprehension of the process of teaching and learning. The self-determination theory comprehend that human being is moved by satisfaction of basic psychological needs such autonomy, competence and belonging, having motivational styles that goes from demotivation to an intrinsically motivated behavior. The aim of the present article was to investigate the motivation to learn in $\mathbf{2 0}$ undergraduate students of Psychology in a private university in the city of São Paulo. The results corroborate the literature once the students presented motivational profiles more autonomously motivated, and the existence of different motivational orientations simultaneous. Was discovered a significant importance of the participation of environmental factors such as teacher and task value in promoting motivation to learn, rescuing the need for an education that makes possible the connection between theory and professional practice enabling to have a sense of what is learned.
\end{abstract}

Keywords: motivation; learning; education; self-determination theory; college students.

${ }^{1}$ Endereço para correspondência: Johny Welton Brito da Silva, Rua Caparaó, 205, Vila Formosa - São Paulo SP - Brasil. CEP: 03364-020. E-mail: johny.brito@gmail.com. 

PSICOLOGÍA

\begin{abstract}
Resumen: El estudio de la motivación ha mostrado un valor significativo en la comprensión de los procesos de enseñanza y aprendizaje. La teoría de la autodeterminación de que el hombre es motivado por la satisfacción de las necesidades psicológicas básicas de autonomía, competencia y pertenencia, teniendo estilos motivacionales que van desde la motivación para el comportamiento intrínsecamente motivados. El presente estudio tuvo como objetivo investigar la motivación para aprender en 20 estudiantes de Psicología de una universidad privada en la ciudad de São Paulo. Los estudiantes estaban perfiles motivacionales más autónomas, así como la existencia simultánea de diferentes orientaciones motivacionales, aunque las dificultades epistemológicas han surgido en la distinción entre la intrínseca y extrínseca. Toma pasos hacia una educación que invite a admirar el mundo y ser capaz de practicar un movimiento que repensar la teoría y producir nuevo conocimiento.
\end{abstract}

Palabras clave: motivación; aprendizaje; educación; teoría de la autodeterminación; universitarios.

Da mesma forma que outros níveis da educação formal, a universidade se compõe como espaço transpassado por questões ditas motivacionais. Nesse sentido, pesquisas vêm sendo desenvolvidas com o objetivo de explorar a qualidade motivacional desses estudantes. Compreendendo que o estudo da motivação possui relevância social no aprimoramento do processo ensino-aprendizagem e especial valor técnico-científico à área de psicologia, o presente estudo visa contribuir para esse campo teórico a partir da investigação da motivação para aprender entre estudantes universitários do curso de Psicologia de uma universidade privada de São Paulo, norteando-se principalmente pela indagação sobre o que motiva esses sujeitos a aprender.

Estudados ao longo de muitos anos e por diversas abordagens e expoentes, a motivação e o aprendizado contaram com diferentes conceituações e compreensões. Myers (2006, p. 333), de forma concisa, dirá que motivação "é a energia e a orientação do comportamento, a força que há por trás da nossa ânsia por alimento, do nosso anseio por intimidade sexual, da nossa necessidade de pertencimento e do nosso desejo de realização". Por sua vez, a aprendizagem seria "uma mudança relativamente permanente no comportamento de um organismo devido à experiência" (Myers, 2006, p. 224). Em realidade, cada um desses conceitos possui uma enorme extensão de conhecimento difícil de ser delimitado. Dentro desse campo, uma área que vem se dedicando com afinco à investigação da união desses fenômenos, ou seja, a motivação para aprender, são as teorias cognitivas e sociocognitivas. Dentre estas, pode-se fazer especial menção à teoria da autodeterminação.

A teoria da autodeterminação, embasada principalmente nos trabalhos de Edward Deci e Richard Ryan (1985, apud Bzuneck \& Guimarães, 2010), parte do pressuposto de que o indivíduo é dotado naturalmente de uma propensão ao desenvolvimento e à autorregulação, movido por necessidades específicas de competência, autonomia e vínculo. Essas necessidades psicológicas básicas, quando satisfeitas no ambiente de sala de aula, favorecem a atuação ativa dos estudantes e sua satisfação (Bzuneck \& Guimarães, 2010).

Sendo assim, a teoria da autodeterminação compreende que o ser humano é intencional e se dirige com finalidades ao mundo para satisfação de necessidades 
básicas. A motivação para aprender, por vezes estudada por meio de uma dicotomia entre motivação intrínseca (relativa ao comportamento que é motivado pela atividade em si e a satisfação inerente a ela) e motivação extrínseca (a atividade é meio para atingir certos eventos ou escapar deles), passou a ser compreendida pelos teóricos da autodeterminação, principalmente Deci e Ryan, não apenas como uma polaridade, mas também como um continuum que pode ir da desmotivação, passando pela motivação extrínseca e por suas diversas regulações (externa, introjetada, identificada e integrada), até a motivação intrínseca. Na motivação extrínseca por regulação externa, o indivíduo age essencialmente sob controle de contingências externas, com pouquíssima autonomia na ação, faz algo para obter resultados que deseja ou evitar consequências coercitivas. Por regulação introjetada entende-se a motivação mantida por aspectos externos, mas, nesse caso, há um aumento da autonomia em razão do fato de que as consequências não são administradas por outros, mas pela própria pessoa. A motivação extrínseca por regulação identificada é uma forma autônoma e autodeterminada da regulação extrínseca, e o sujeito com essa orientação se identifica com o valor subjacente a um determinado comportamento e o aceita, considerando-o como próprio.

A regulação integrada é a forma mais completa de internalização do controle externo, o indivíduo se identifica com o valor de um comportamento e assimila as regulações ao self, porém se difere da motivação intrínseca por ter um valor instrumental presumido, ou seja, visa a alguns resultados separados da satisfação do comportamento em si. Em contraposição, a desmotivação se constitui pela ausência de motivação, não há regulação e o locus de causalidade é impessoal; há, portanto, ausência de intenção, desvalorização e falta de controle (Almeida, 2012). Desse modo, toma-se a ideia de que a motivação é um processo que se transforma por meio de um mecanismo de introjeção que vai do indivíduo que é motivado exclusivamente por fatores externos a ele até o indivíduo que é motivado pela atividade em si (Bzuneck \& Guimarães, 2010).

E válido destacar que as motivações extrínseca e intrínseca entendidas como processo não são estanques nem necessariamente excludentes, pelo contrário, existe uma correlação significativa e positiva entre as duas variáveis indicando que ambas tendem a desenvolver-se conjuntamente e possuem efeitos positivos sobre o aprendizado (Boruchovitch, 2008; Cardoso \& Bzuneck, 2004; Zenorini \& Santos, 2010a, 2010b).

Ruiz (2003) fez um trabalho de revisão de literatura de considerável amplitude na investigação das variáveis que influenciam a motivação para aprender, utilizando-se especialmente do modelo de Pintrich. Esse modelo considera como variáveis específicas para a motivação: o contexto sociocultural (atitudes, crenças e comportamentos que os estudantes trazem para a universidade), os fatores relacionados ao ambiente de sala de aula (tipos de tarefas dadas, o comportamento do professor e dos métodos instrucionais utilizados), os fatores internos aos estudantes (sentimentos, percepções, necessidades e metas) e o comportamento motivado em si (comportamentos reais 
observáveis), demonstrando a importância de fatores históricos, ambientais e de interesse na motivação para o aprendizado.

Pesquisas também vêm sendo feitas para compreender a motivação para aprender em estudantes universitários. O estudo exploratório desenvolvido por Almeida (2012) a respeito do perfil motivacional dos estudantes universitários e dos fatores envolvidos com a motivação em aprender compreendeu uma variedade de observações a serem consideradas. De acordo com a autora, os estudantes possuem um perfil de motivação autônoma em que apresentam uma consciência mais clara da importância de frequentar o curso superior e se encontram em uma fase de reconhecimento e valorização dos estudos (portanto, com maiores pontuações em orientações mais intrinsicamente motivadas). Resultados similares a esse foram encontrados por Alcará (2007) e Engelmann (2010). Contudo, Almeida (2012) também faz a ressalva de que os estudantes estão dentro de uma estrutura que controla grande parte do seu comportamento, nem sempre contribuindo para o desenvolvimento da uma motivação autônoma.

Ainda de acordo com Almeida (2012), é importante que os estudantes possam atrelar-se a trabalhos de investigação científica e de maior contato com a comunidade em que se inserem, como forma de ampliar o sentido da aprendizagem, despertando maior implicação dos graduandos nas atividades universitárias, propiciando assim um maior envolvimento acadêmico e qualidade motivacional. É válido retomar que quanto melhor a qualidade da motivação, maior a tendência de esforço nos estudos e interesse em atuar na área. Engelmann (2010) e Machado (2009) também ressaltam que a satisfação das necessidades de autonomia, competência e pertencimento (vínculo) é essencial para desenvolver orientações autodeterminadas que estão relacionadas com a motivação intrínseca, resultando em maior empenho, melhor aproveitamento da aprendizagem, persistência e criatividade.

No tocante à promoção de determinadas orientações motivacionais, estudos têm mostrado que o estilo motivacional do professor irá influir sobre a qualidade motivacional dos estudantes. Há dois estilos motivacionais: controlador (o professor elabora plano de aula fechado, faz uso de ameaças, punições e recompensas, e tem por fim último cumprir objetivos) e promotor de autonomia (estimula a realização de trabalhos de forma autodeterminada e incentiva as iniciativas dos estudantes) (Guimarães \& Boruchovitch, 2004; Machado, 2009; Machado, Guimarães, \& Bzuneck, 2006; Zanatto, 2007).

Para Ruiz (2005), com base no estudo das variáveis que interagem com a motivação para aprender, a motivação dos estudantes está fundamentada principalmente no interesse, na importância e na utilidade que percebem nas suas tarefas acadêmicas. Essa conclusão supõe o significativo espaço que a percepção de instrumentalidade e o valor atribuído à tarefa possuem na motivação para aprender. O valor da tarefa está atrelado à percepção dos estudantes sobre o quão interessantes, úteis e importantes são as matérias escolares. Por sua vez, essa variável tem importância prioritária do ponto de vista da motivação, sendo possível que esta se sobreponha inclusive às condições negativas e limitantes próprias a estudantes que trabalham e estudam (Ruiz, 
2008). Dados semelhantes a esse foram indicados por Almeida (2012) e Alcará (2007) em estudos com universitários.

Entendendo a motivação para aprender como aspecto multideterminado com significado e origem nas relações e concepções que o indivíduo mantém com o ambiente, e sendo esse assunto de valor em perspectivas sociais e científicas para a população estudada, o presente estudo teve como objetivo investigar a motivação para aprender em estudantes universitários.

\section{Método}

\section{Participantes}

Participaram da pesquisa 20 estudantes universitários de Psicologia de uma instituição particular de ensino da cidade de São Paulo, com média de idade de 22 anos, sendo 15 do sexo feminino e 5 do sexo masculino. Tais alunos estavam matriculados no segundo ou no oitavo semestres do período diurno. A escolha dos semestres permitia comparar variáveis motivacionais em alunos do início e do final do curso, tratando-se de uma amostra não probabilística.

\section{Instrumento}

Foram realizadas entrevistas semiestruturadas com oito questões norteadoras para descrever: 1. as concepções dos participantes sobre motivação para aprender; 2. a avaliação sobre o próprio estado motivacional 3. os fatores motivacionais (em si e nos colegas de classe). $O$ roteiro de entrevista foi previamente avaliado com dez participantes.

\section{Procedimento}

As entrevistas foram gravadas e transcritas. Posteriormente, seus conteúdos foram agrupados segundo as unidades de sentido presentes no discurso dos entrevistados. Tomou-se por base o proposto por Sampieri, Collado e Lucio (2006), sendo feita a divisão das unidades de análise em frases ou enunciados que carreguem sentido completo. As unidades foram agrupadas por meio de um sistema de códigos que indicavam sua localização e classificação (por exemplo: 1,4, MIG, S2; que significa unidade 1,4 do colaborador 2, categorizado como motivação intrínseca relativa a prazer ou gosto pela atividade). Essa forma de identificação dos dados permitiu o agrupamento nas respectivas categorias criadas, bem como a identificação de singularidade ou regularidade das falas, ou seja, se determinado aspecto referia-se à fala de um colaborador ou de vários. A análise após a coleta ocorreu em duas etapas: a primeira consistiu na compreensão das unidades de análise e criação de categorias de acordo com cada pergunta da entrevista, isoladamente; e a segunda considerou todas as unidades de análise de cada categoria criada a partir de todas as entrevistas. O projeto foi aprovado pelo Comitê de Ética em Pesquisa da Universidade Presbiteriana Mackenzie (UPM). Todos os sujeitos participaram de forma livre e esclarecida. 


\section{Resultados e discussão}

O processo de codificação resultou na criação de dez categorias e suas respectivas subcategorias, como exposto no Quadro 1. As categorias foram definidas simultaneamente ao processo de codificação.

\section{Quadro I. Categorias e subcategorias do conteúdo das entrevistas}

\begin{tabular}{ll}
\hline Categoria/Subcategoria & Definição \\
\hline Motivação extrínseca & \\
Obtenção de ganhos futuros e objetivos (MEF) & $\begin{array}{l}\text { Descreve a motivação como algo responsável pela } \\
\text { obtenção de ganhos futuros e pelo alcance de metas } \\
\text { e objetivos. }\end{array}$ \\
Relação com fatores externos (MEE) & $\begin{array}{l}\text { Descreve a motivação como dependente de fatores } \\
\text { externos ao indivíduo. }\end{array}$
\end{tabular}

Motivação intrínseca

Prazer ou gosto (MIG)

Descreve a motivação na relação com atividades que

Iniciar e/ou persistir (MIP) geram prazer ou na realização de algo que se gosta.

Vontade (MIV)

Descreve a motivação como responsável por iniciar um comportamento ou por persistir nele.

Desenvolvimento pessoal (MID)

Descreve a motivação como vontade de fazer algo ou algo que estimula a vontade.

Descreve a motivação no desenvolvimento das próprias potencialidades.

Interesse (MII)

Descreve a motivação como ter interesse por algo.

Sentimentos, crenças e percepções (MIS)

Descreve a motivação na relação com sentimentos, crenças e percepções.

Desmotivação

Não vê sentido ou utilidade (DS)

Não se identifica ou não gosta (DG)

Fatores externos (DF)

Motivos biológicos e cognitivos (DB)

Sentimentos, crenças e percepções (DSE)

Diversos (DI)
Descreve a desmotivação em função de considerar o conteúdo apresentado sem importância, necessidade ou sentido.

Descreve a desmotivação em função de não gostar da disciplina e não ter interesse.

Descreve a desmotivação na relação com variáveis ambientais, como o professor e os colegas.

Descreve a desmotivação relacionada a fatores de ordem orgânica ou cognitiva, como cansaço e pressão.

Descreve a desmotivação na relação com sentimentos, crenças e percepções.

Itens em divergência, isolados ou sem significado para análise. 


\section{Quadro I. Categorias e subcategorias do conteúdo das entrevistas (conclusão)}

\begin{tabular}{ll}
\hline Categoria/Subcategoria & Definição \\
\hline Indefinição (I) & $\begin{array}{l}\text { O discurso é uma resposta imprecisa ou o sujeito } \\
\text { alega não saber falar sobre o perguntado. }\end{array}$ \\
\hline
\end{tabular}

Nível de motivação para o aprendizado (NMP)

Presente

Refere-se à descrição de quanto o indivíduo se sente motivado para aprender, especialmente dentro de sala de aula, no momento atual.

Passado

Refere-se à descrição de quanto o indivíduo se sente motivado para aprender nas relações com a educação no passado.

Nível com variância

Refere-se à descrição do nível de motivação como dependendo de situações específicas.

Experiência fora do contexto (MFC)

O discurso descreve experiências passadas ou presentes, características pessoais e situações que não estão dentro do contexto acadêmico e de educação, e que influenciaram sua motivação.

Escolha do curso

Influência pessoal (CP)

Refere-se a unidades em que os participantes descrevem e ressaltam experiências pessoais e familiares, assim como características próprias como motivos para escolha do curso.

Influência pelo contato com a profissão (CC)

Refere-se a unidades que descrevem o contato com profissional ou informações da psicologia como uma das variáveis na escolha do curso.

Influência pelas características da profissão (CCP)

Refere-se a unidades que descrevem características da profissão ou do curso, assim como as potencialidades deles, como ligados à motivação para aprender.

Sentimento de eficácia (SE)

Refere-se à quantificação e descrição dos participantes sobre o quanto se sentem capazes para realizar as atividades propostas em sala de aula.

Fonte: Elaborado pelos autores.

A motivação intrínseca surgida na fala dos colaboradores foi ao encontro da definição clássica do termo na literatura, à medida que trouxe concepções acerca de realizar uma atividade por gostar e/ou gerar prazer - "Motivação é o que uma pessoa sente pra poder fazer uma coisa com prazer, acho" -, assim como pelo interesse ou pela vontade de realizar uma atividade e/ou pelo desenvolvimento de conhecimentos e habilidades. Considerando o modelo de Pintrich (Ruiz, 2003), também as variáveis sentimentos, crenças e percepções compuseram noções da categoria motivação intrínseca. Como é possível observar, a motivação intrínseca como utilizada aqui recupera um espectro maior de fatores envolvidos na motivação autodeterminada. Contudo, aparentemente, teria se diferenciado do 
exposto por outros autores a respeito do perfil do estilo motivacional de estudantes brasileiros, como o estudo de Boruchovitch (2008), uma vez que os discursos que se referiam à motivação intrínseca tiveram uma representatividade significativamente menor que a motivação extrínseca. Quando se compararam as duas grandes categorias, a motivação extrínseca foi responsável por 174 unidades de análise, e a intrínseca, por apenas 91.

Ainda no que se refere à análise qualitativa, há uma dificuldade de caráter epistemológico. Trata-se da dificuldade de distinguir o que é considerado interno ou externo, ou seja, onde estão o locus de causalidade do comportamento e a regulação da motivação. Por exemplo, quando se analisou a resposta do participante S5 à questão sobre como ele entende o conceito de motivação, obteve-se o seguinte discurso: "Motivação eu acho que é como se fosse uma inspiração própria, é a pessoa fazer aquilo que gosta sem precisar que outra pessoa mande, acho que motivação tem que tá dependente da pessoa que faz lá, no caso estudar". Essa unidade foi aqui classificada na categoria "Motivação intrínseca relacionada ao prazer ou gosto", sendo ressaltado na fala o autocontrole no processo motivacional, ou seja, a autodeterminação. Esse mesmo participante, ao responder ao item sobre o que o motiva a aprender, afirmou:

Principalmente no futuro, né?, eu vou colher meus frutos mais pra frente, mas agora é muito bom eu conseguir concluir o curso com notas boas, acho que é importante pra mim primeiramente e independente de qualquer outra pessoa. [...] O orgulho da família assim, uma honra também, a sociedade assim.

Nessa situação, o participante S5 descreve os fatores que o motivam a aprender: obtenção de ganhos futuros (os "frutos" a serem colhidos), notas boas e outros fatores ambientais, como orgulho da família e reconhecimento social. Com base nisso, é possível inferir que as distinções entre o indivíduo e o ambiente transitam em uma linha tênue, em que as respostas de realizar atividades e tarefas por prazer, gosto, interesse e vontade devem ser seguidas pelo questionamento sobre o que faz com que certa atividade adquira essas propriedades para o indivíduo.

A motivação extrínseca também manteve aproximações com a literatura, uma vez que foram comuns aparições da motivação imbricada a ganhos futuros e alcance de objetivos (53 unidades):

Eu acho que meu futuro, né?, se eu não estivesse aqui, eu não ia ter um futuro concreto mais pra frente. Então, eu acho que é isso. O que me motiva estudar, ser uma aluna boa, é saber que mais pra frente eu serei uma boa profissional.

Todavia, diferentemente da concepção de obtenção de ganhos arbitrários como nota em avaliações, dinheiro ou recompensas sociais, o aspecto predominante no discurso dos participantes refere-se comumente a atuar na área de formação, tornar-se um bom profissional e realizar futuramente especializações em áreas de interesse. Logo, entende-se que as motivações giram em torno de realizações vinculadas diretamente à formação e ao 
aprender, o que cria dificuldades na divisão do que está ou não relacionado à atividade em si. Esse fenômeno está mais próximo do conceito de motivação extrínseca regulada por identificação ou integração, um limiar entre a motivação extrínseca e a intrínseca (Bzuneck \& Guimarães, 2010), já que os participantes assumem o compromisso pessoal com o aprendizado e reconhecem a importância deste na formação para atuação profissional futura, ainda que não necessariamente se crie uma relação afetiva, como o gosto e o prazer pela formação na sua integralidade. É preciso considerar também o caráter de instrumentalidade que é inerente ao ensino superior, uma vez que este tem como uma de suas finalidades a inserção no mercado de trabalho por meio da área escolhida. Essa ideia e interpretação dos dados se aproximam da literatura recente a respeito da motivação para aprender em estudantes universitários (Alcará, 2007; Almeida, 2012; Engelmann, 2010), em que universitários apresentaram perfis motivacionais mais autodeterminados, assim como reconhecimento da importância dos estudos e valorização do aprendizado. O discurso dos participantes pouco evidencia controles externos como fuga de coerção ou obtenção de ganhos arbitrários, mas condizem mais com o reconhecimento da importância da graduação como forma para realização de atividades posteriores, portanto implicando uma motivação extrínseca de caráter mais autônoma e autodeterminada.

Ainda a respeito da motivação extrínseca, nos termos utilizados nesta pesquisa, uma subcategoria que abrangeu uma grande quantidade de unidades (121 unidades) refere-se à motivação para aprender relacionada a fatores externos. Essa subcategoria distancia-se da compreensão de motivação extrínseca como relacionada apenas à obtenção de benefícios e à esquiva de situações aversivas. Nesse contexto, essa subcategoria corresponde a variáveis ambientais que são influências na maior ou menor motivação para aprender dos estudantes. Entre essas variáveis, surgiram: apoio da família e de colegas, ambiente tranquilo na sala de aula, trabalhos acadêmicos, provas, disciplina curricular (matéria) e evitamento de dependências de semestres anteriores. Todavia, um destaque amplamente significativo foi dado ao professor (68 unidades): "Como o professor ensina, dando exemplos da vida, não sei, dando exemplos mais realistas assim, não só dando a teoria, dando a teoria e os exemplos pra gente conseguir ligar com a teoria, eu acho que o que mais motiva é isso".

Os participantes descreveram como características importantes para que o professor possa motivar os estudantes: a capacidade de ouvir, responder a perguntas, compartilhar a experiência profissional, fazer uso de exemplos, abrir espaço a reflexão, expor o conhecimento de forma clara, propiciar a integração da teoria-prática e consequentemente manter maior contato com a realidade profissional. Como indicado por Guimarães e Boruchovitch (2004), o estilo motivacional do professor, ou seja, a crença e confiança em certas estratégias de ensino, pode ser uma importante influência na orientação motivacional dos estudantes. Em literatura, os estilos motivacionais dos professores são comumente descritos como controladores ou promotores de autonomia. O discurso dos participantes refletiu características como saber ouvir e mostrar a importância para aprender determinado conteúdo (entendido aqui nos termos de dar exemplos de utilidade dos conteúdos na profissão), que se aproximam das características de professor com estilo motivacional de promoção 
de autonomia (Guimarães \& Boruchovitch, 2004). De acordo com Machado (2009), uma série de características do contexto escolar favorece o suporte da autonomia dos estudantes, como demonstrar a relevância do que é estudado, oferecer opções de escolha, dar espaço para manifestação de sentimentos e de insatisfação com as tarefas desinteressantes e estimular o pensamento independente.

Quanto às variáveis que influenciam a desmotivação em aprender, os participantes citaram: falta de utilidade do conhecimento adquirido, desinteresse pelo conteúdo, não identificação com o conteúdo a ser aprendido, aspectos biológicos como o cansaço e fatores ambientais físicos (temperatura, ruído etc.). Novamente, os fatores socioambientais foram emergentes nas falas dos participantes, sendo congruente com o exposto a respeito dos aspectos que os motivariam a aprender. Os colegas tornam-se uma variável considerável na desmotivação quando desinteressados, quando atrapalham o rendimento da aula e pela conversa excessiva. A respeito da falta de utilidade do conhecimento adquirido, pode-se interpretar que, segundo Ruiz (2008), o valor da tarefa está atrelado à percepção dos estudantes sobre o quão interessantes, úteis e importantes são as matérias escolares.

De acordo com os participantes, professores considerados monótonos contribuem para a desmotivação no processo de aprendizagem, assim como os que demonstram pouco interesse pelo que estão ensinando, exigem excesso de atividades, possuem dificuldade na condução da sala, usam excessiva ou exclusivamente um único recurso didático, não realizam um convite reflexivo e de aproximação entre teoria e prática na sala de aula, e são incongruentes entre sua postura profissional e seu discurso. Alguns dos dados surgidos convergem com o alerta feito por Almeida (2012) ao expor que a capacidade do professor de atribuir valor a determinado conteúdo para a formação profissional, mostrando a relação entre o que é ensinado e a práxis, pode contribuir para a significação que os participantes dão aos estudos e para a consequente melhoria do quadro motivacional dos estudantes. Também foi destacado por Alcará (2007) a importância que a percepção de instrumentalidade e a perspectiva de tempo futuro têm na motivação para aprender nas suas formas mais autônomas, logo deve ser uma prática estimulada entre os docentes a explicitação do valor e a aplicação futura do conteúdo aprendido.

Os participantes têm uma percepção de si mesmos como estudantes motivados: 17 deles indicaram possuir motivação maior ou igual a sete em uma escala de 0 a 10 . Contudo, devem-se considerar tanto os possíveis aspectos de desejabilidade social como o fato de significativa parte dos indivíduos apontar que a sua motivação para aprender não é igual para todos os componentes da grade curricular. Certas disciplinas despertam interesse, enquanto outras não. Isso pode sugerir que é necessário um maior cuidado na investigação da motivação para aprender em cursos de nível superior, visto que os participantes possuem interesses e motivos pessoais, assim como influências ambientais que determinam uma heterogeneidade na vontade por aprender ao longo da formação e nas diferentes disciplinas. Outro indicativo que pode compor essa heterogeneidade é a presença das variáveis que os participantes relataram como responsáveis pela sua motivação dentro da sala de aula: 18 acreditam que há a presença tanto de variáveis motivadoras como 
desmotivadoras em sala de aula, e destes, oito creem que há predominância de variáveis motivadoras. Pode-se supor a possibilidade de uma correlação positiva entre o maior número de variáveis motivadoras, com a maior percepção de si mesmos como motivados. Uma vez que essas variáveis não se referem apenas a interesse e gosto pela disciplina, e vontade de aprender, mas também a aspectos relacionados à motivação extrínseca, como alcance de objetivos, e fatores socioambientais, como o professor, os dados reforçam a hipótese da significativa importância das variáveis externas como promotoras da motivação. Assim como sugerido por Ruiz (2005), com base nas mudanças das características motivacionais de estudantes no início e ao longo do curso, as variáveis ambientais e situacionais possuem força suficiente na influência da motivação, demandando assim mais investigações sobre essas variáveis presentes nos diferentes ambientes e contextos de aprendizagem.

Quanto ao envolvimento nas tarefas e atividades acadêmicas, o discurso dos participantes reflete o exposto em literatura (Boruchovitch, 2008; Cardoso \& Bzuneck, 2004; Zenorini \& Santos, 2010a, 2010b), mostrando que os estudantes dificilmente apresentam uma orientação motivacional pura, mas realizam as atividades tanto pelo valor do aprendizado inerente a ela como para obtenção de notas e consequente aprovação na disciplina. Nesta pesquisa, 17 indivíduos afirmaram que fazem provas e trabalhos tanto pelo valor inerente à atividade quanto como critério para concluir a disciplina e três participantes disseram realizar a atividade exclusivamente para concluir a disciplina. Nenhum participante afirmou realizar essas atividades exclusivamente pelo valor inerente à atividade. A regulação apenas por motivos externos torna-se relevante à medida que, como indicado por Bzuneck e Guimarães (2010,) estudantes orientados dessa forma tendem a não enfrentar desafios, perder iniciativa e satisfazer-se com reproduções do conteúdo ou simples término da tarefa, sem preocupação com qualidade.

Nota-se que as diferenças entre os participantes do segundo e oitavo semestres não foram qualitativamente discrepantes, pois os participantes partilham entre si muitas das concepções acerca do que os motiva ou não a aprender. Os estudantes do segundo semestre obtiveram média na sua percepção a respeito da própria motivação para aprender maior que os estudantes do oitavo semestre, 8,5 e 6,6, respectivamente, mostrando uma possível diminuição da motivação para aprender ao longo do curso, que poderia ser confirmada ou refutada a partir de um estudo longitudinal. Uma hipótese para compreender a diferença pode ser que os estudantes do oitavo semestre estejam mais dirigidos às atividades práticas e profissionais, vinculando-se menos às atividades propostas em sala de aula, tanto em razão dos primeiros contatos com a prática clínica como pela proximidade com a atuação profissional, como destaca um dos participantes:

Como uma professora minha, até ela viu, ela deu aula no primeiro semestre pra gente, aí ela falou: "Gente, o que é que tá acontecendo, vocês tão diferentes, vocês tão dispersos?". E ela perguntou o que é que estava acontecendo. Aí, uma amiga minha falou por todos de que nesse momento a gente não aguenta mais sala de aula, a gente já tá saturado, então a gente quer outras coisas, e aí, desde aquele dia, minha professora tá trazendo casos, toda aula ela traz caso e tal, que prende muito mais a sala, sem dúvida. 


\section{Considerações finais}

O estudo da motivação para aprender compreendida pela fala dos estudantes corroborou as discussões existentes na literatura ao demonstrar a complexidade desse conceito na sua riqueza de determinações e influências. Foi possível perceber que a motivação para aprender na universidade condensa características próprias que a distinguem das formas de controle exclusivamente externo ou exclusivamente interno. Na prática, isso indica que já não se trata de estudantes que se relacionam com o conhecimento pela coerção de fatores ambientais (como pais e professores) ou como forma única e exclusiva de atingir algum ganho por si (notas em avaliações, dinheiro, diploma), tampouco são estudantes que prezam o conhecimento exclusivamente por uma relação de prazer e gosto pelo aprendizado. Fala-se em realidade de participantes que reconhecem a importância do que estudam e assumiram um compromisso pessoal pelo aprender e que agora têm a opção de selecionar as atividades e aplicar-se a elas dentro da universidade que são de maior interesse para a vida profissional que escolheram ou estão escolhendo, com diferentes estilos motivacionais operando ora simultaneamente e ora separadamente.

Também se faz importante a recuperação de que, quando se estuda a motivação como movimento intencional, recolocam-se os participantes como seres no mundo, que se motivam e desmotivam na troca com experiências, objetos e pessoas do contexto acadêmico (e mesmo fora). Isso foi demonstrado pela significativa presença do professor como variável responsável pela motivação e desmotivação em aprender. Outro aspecto de destaque é a importância na compreensão da necessidade, da aplicabilidade e da atuação da teoria na prática, ou seja, auxiliar os estudantes a identificar o valor da tarefa, o "motivo" pelo qual se estuda algo, e enxergá-lo no cotidiano profissional. Integrando essas informações é possível perceber que o manejo de certas condições dentro de sala de aula, associadas principalmente à possibilidade de o professor apoiar os alunos na articulação teoria e prática e na diversificação de métodos de ensino, é alternativa interessante de intervenção. Desse modo, o reconhecimento das variáveis ambientais retira da motivação para aprender o caráter de atributo individual cristalizado, para um processo que se dá em uma determinação recíproca com o ambiente.

Sendo assim, o objetivo de explorar a motivação para aprender em estudantes de Psicologia foi alcançado, bem como o objetivo de investigar possíveis diferenças entre o segundo e o oitavo semestres do curso. Porém, apesar de identificada uma significativa redução no nível de motivação para aprender do segundo para o oitavo semestre e a importância de contextos diferentes na motivação, como o contato com as primeiras atividades clínicas no final do curso, não foi possível apontar mais profundamente, por limitação do estudo, as similaridades e diferenças entre os semestres. A realização de estudos longitudinais poderia vir a tratar com maior riqueza esses indicadores.

O presente estudo possui limitações quanto ao número de estudantes (próprio ao método de trabalho escolhido), mas principalmente de contexto, uma vez que a amostra obteve características homogêneas oriundas de uma única instituição. $O$ trabalho com o roteiro semiestruturado também manteve limitações quanto à melhor 
identificação de locus de causalidade dos comportamentos e às fontes de regulação da motivação, sendo interessante a realização de estudos que façam uma análise mais detalhada do discurso de cada participante na identificação desses componentes. Também são imprescindíveis investigações que façam uso de outros métodos de exploração do assunto, como forma de evitar variáveis de distorção como a desejabilidade social presente em instrumentos de autorrelato. Sendo assim, novas pesquisas que utilizem concomitantemente diferentes instrumentos, como escalas (alvo de expressivas investigações recentemente), entrevistas (com estudantes e professores), observação em sala de aula e outros contextos, podem ser valiosas fontes de conhecimento sobre o assunto. É importante ressaltar também que o instrumento escolhido e o método delineado tiveram por foco avaliar a motivação para aprender dos estudantes vinculada ao contexto de sala de aula universitária. Sendo assim, devem-se evitar, como em qualquer pesquisa no campo das ciências humanas, possíveis generalizações dos resultados a todo o significado que o aprender engloba nas atividades humanas.

Por fim, o entendimento de que o que move o aprender está em uma relação contínua com o mundo resgata o sentido de potência na educação pela conquista da autonomia e de relações com o conhecimento que se façam de forma prazerosa e consciente. Com base nas discussões realizadas, é fundamental que sejam dados passos no sentido de uma educação que possa ser mais problematizadora e que convide os estudantes a admirar o mundo em parceria com os educadores. Não basta apenas reconhecer a prática da teoria. Professores e alunos devem ser capazes de, em um movimento de práxis, repensar a teoria e produzir novos conhecimentos. Uma vez desafiados, ambos devem ser motivados pelo mundo.

\section{Referências}

Alcará, A. R. (2007). Orientações motivacionais de alunos do curso de Biblioteconomia de uma universidade pública do norte do Paraná. Dissertação de mestrado, Universidade Estadual de Londrina, Londrina, PR, Brasil.

Almeida, D. M. S. (2012). A motivação do aluno no ensino superior: um estudo exploratório. Dissertação de mestrado, Universidade Estadual de Londrina, Londrina, PR, Brasil.

Boruchovitch, E. (2008). Escala de motivação para aprender de universitário (EMA-U): propriedades psicométricas. Avaliação Psicológica, 7(2), 127-134.

Bzuneck, J. A., \& Guimarães, S. E. R. (2010). A promoção da autonomia como estratégia motivacional na escola: uma análise teórico e empírica. In E. Boruchovitch, J. A. Bzuneck \& S. E. R. Guimarães (Orgs.). Motivação para aprender: aplicações no contexto educativo. Petrópolis: Vozes.

Cardoso, L. R., \& Bzuneck, J. A. (2004). Motivação no ensino superior: metas de realização e estratégias de aprendizagem. Psicologia Escolar e Educacional, 8(2), 145-155. 
Engelmann, E. (2010). A motivação de alunos dos cursos de artes de uma universidade pública do Norte do Paraná. Dissertação de mestrado, Universidade Estadual de Londrina, Londrina, PR, Brasil.

Guimarães, S. E. R., \& Boruchovitch, E. (2004). O Estilo Motivacional do Professor e a Motivação Intrínseca dos Estudantes: Uma Perspectiva da Teoria da Autodeterminação. Psicologia Reflexão e Crítica, 17(2), 143-150.

Guimarães, S. E. R., Bzuneck, J. A., \& Boruchovitch, E. (2010). Instrumentos brasileiros de avaliação da motivação no contexto escolar: contribuições para pesquisa, diagnóstico e intervenção. In E. Boruchovitch, J. A. Bzuneck \& S. E. R. Guimarães (Orgs.). Motivação para aprender: aplicações no contexto educativo. Petrópolis: Vozes.

Machado, A. C. T. A. (2009). Interações professor-aluno: preferência por autonomia ou controle. Dissertação de mestrado, Universidade Estadual de Londrina, Londrina, PR, Brasil.

Machado, A. C. T. A., Guimarães, S. E. R., \& Bzuneck, J. A. (2006). Estilo motivacional de professor e a motivação extrínseca dos estudantes. Semina: Ciências Sociais e Humanas, 27(1), 3-13.

Myers, D. (2006). Psicologia (7a ed.). (E. J. Custódio da Silva, M. A. S. Rouch \& J. M. G. Nunes, Trad.). Rio de Janeiro: LTC.

Ruiz, V. M. (2003). Motivação na universidade: uma revisão da literatura. Revista Estudos de Psicologia, 20(2), 15-24.

Ruiz, V. M. (2005). Aprendizagem em universitários: variáveis motivacionais. Tese de doutorado, Pontifícia Universidade Católica de Campinas, Campinas, SP, Brasil.

Ruiz, V. M. (2008). Valor de tarefas de aprendizagem para universitários de cursos noturnos. Revista Semestral da Abrapee, 12(2), 451- 460.

Sampieri, R. H., Collado, C. H., \& Lucio, P. B. (2006). Metodologia de pesquisa (3a ed.). (F. C. Murad, M. Kassner \& S. C. D. Ladeira, Trad.). São Paulo: McGraw-Hill.

Zanatto, R. (2007). Perfil motivacional de alunos de arquitetura: um estudo exploratório. Dissertação de mestrado, Universidade Estadual de Londrina, Londrina, PR, Brasil.

Zenorini, R. P. C., \& Santos, A. A. A. (2010a). Escala de metas de realização como medida da motivação para aprendizagem. Interamerican Jounal of Psychology, 44(2), 291-298.

Zenorini, R. P. C., \& Santos, A. A. A. (2010b). Teorias de metas de realização: fundamentos e avaliação. In E. Boruchovitch, J. A. Bzuneck \& S. E. R. Guimarães (Orgs.). Motivação para aprender: aplicações no contexto educativo. Petrópolis: Vozes. 